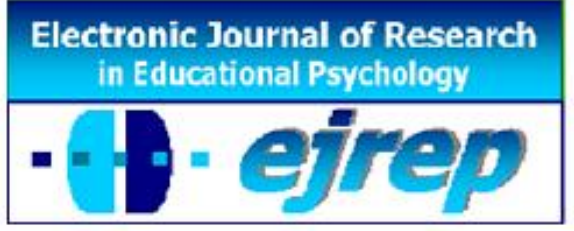

\title{
Action-based Digital Tools: Mathematics Learning in 6-year-old Children
}

\section{Peter J.N. Dejonckheere ${ }^{1}$, Annemie Desoete ${ }^{2}$, Nathalie Fonck $^{1}$, Dave Roderiguez ${ }^{1}$, Leen Six ${ }^{1}$, Tine Vermeersch ${ }^{1}$, and Lies Vermeulen ${ }^{1}$}

\author{
${ }^{1}$ Teacher Department, University College of Vives \\ ${ }^{2}$ Department of Clinical and Health Psychology, Ghent University
}

Belgium

Correspondence: Peter Dejonckheere. Beernegemstraat 10, B-8700 TIELT. Belgium.

E-mail: peter.dejonckheere@vives.be

(C) Education \& Psychology I+D+i and Editorial EOS (Spain) 


\section{Abstract}

Introduction. In the present study we used a metaphorical representation in order to stimulate the numerical competences of six-year-olds. It was expected that when properties of physical action are used for mathematical thinking or when abstract mathematical thinking is grounded in sensorimotor processes, learning gains should be more pronounced in children with stronger motor capacities than in children with rather low motor capacities.

Method. Thirty-four first grade children with a mean age of 6 years and 6 months participated in the experiment with a pre and posttest design. Therefore mouse handling precision, gross and fine motor performances and number line estimation was administered before and after the intervention with a digital number line.

Results. In contrast to what was expected, children that performed below the median in a gross motor task benefitted significantly more from the intervention compared to children with scores above the median for such gross motor tasks.

Discussion and Conclusion. These results do not only highlight the relationship between motor development and math learning but they also show that children with lower motor capacities are possibly more in need of a strong physical appearance whereby the possibilities for action are clearly visible, even in digital tools.

Keywords: Early math learning, Motor abilities, Action, Embodied Cognition. 


\section{Herramientas Digitales Basadas en la Acción: Aprendizaje de las Matemáticas en Alumnos de seis Años Resumen}

Introducción. En el presente estudio, utilizamos una representación metafórica a fin de estimular las habilidades numéricas de niños de seis años de edad. Se espera que, cuando se utilizan las propiedades de la acción física para el pensamiento matemático o cuando el pensamiento matemático abstracto se basa en procesos sensoriomotores, la asimilación del aprendizaje debe ser más pronunciada en niños con capacidades motrices más fuertes que en los niños con capacidades motrices más débiles.

Método. Treinta y cuatro niños de primer grado con una edad media de 6 años y 6 meses participaron en el experimento con diseño de prueba previo y posterior. Por lo tanto la precisión en la manipulación del ratón, las prestaciones motrices gruesas y finas y la estimación de recta numérica se administró antes y después de la intervención con una recta numérica digital.

Resultados. A diferencia de lo que se esperaba, los niños cuyos resultados estaban por debajo de la media en una tarea de motricidad gruesa se beneficiaron significativamente más de la intervención en comparación con los niños con puntuaciones por encima de la media para este tipo de tareas de motricidad gruesa.

Discusión y Conclusiones. Estos resultados no hacen sino resaltar la relación entre el desarrollo motriz y el aprendizaje de las matemáticas, pero también muestran que los niños con capacidades motoras inferiores posiblemente necesiten más un aspecto físico más fuerte mediante el cual las posibilidades de acción son claramente visibles, incluso con herramientas digitales.

Palabras clave: Aprendizaje temprano de las matemáticas, Habilidades motoras, Acción, Personificación del conocimiento. 


\section{Introduction}

In the present study it was investigated to what extent the motor capacities of six-yearolds were able to forecast early math learning with a digital tool in which action control was prominent. Siegler and Ramani (2008) already investigated to what extent playing a numerical board game enhanced low-income children's knowledge of numerical magnitudes and to what extent a general linear representation of numerical magnitude could be encouraged. During this study children of four years old received four individual 15-minute sessions over a period of two weeks. Two situations were created. In the first situation, with the number game group, children played a linear board game with squares labelled 1-10. The other group, the colour game group, played the same game with the exception that the squares on the board included colours instead of numbers. Results indicated that after the sessions with the number board, the knowledge of numerical magnitude in low-income children had become indistinguishable from the knowledge of children from middle-income backgrounds. This effect was absent in the colour game group.

\section{Math Learning and Action}

In the present study we replicated Siegler and Ramani's experiment but we posed other research questions. We first designed a digital tool based on the author's number board game. In our opinion, digital tools in the form of games need to play a bigger role in educational contexts with young children, since they often evoke an extended attention span and accessibility through the use of action, graphic animation and visual effects (Räsänen, Salminen, Wilson, Aunio \& Dehaene, 2009). However, a lot of digital tools aimed to teach mathematics are nothing more than drill-and-practice tasks in which a subject is asked to resolve a mathematical problem or to select the right answer in a multiple choice task. However, digital tools for learning should be more focused on real-life situations, since metaphorical representations serve as an interface supporting users to use actions and objects taken from a physical world (Antle, Corness \& Droumeva, 2009). As long as cognitive activity is strongly coupled to the environment, a child can learn in such an artificial environment (Winn \& Windschitl, 2001). Moreover, the use of animated physical representations on the one hand and the fact that a user can act on the other hand, opens up opportunities to direct a child's attention on key structural features that are needed for a more skilled learning more easily. For instance, the construction of the Virtual Puget Sound, a simulation of physical oceanography, enable users to learn how water moves in the ocean by interacting with representations 
that show the behaviour of tides and currents (Winn, 2003). In such a representation an abstract problem is not only modelled for the perceiver, he or she is allowed to regulate a number of action parameters over time. The corner stone of this digital tool is then action control. Action control may lead to an increased perceptual sensitivity (Winn, 2003). In other words, the system becomes alert. It can be suggested then that the results of Siegler and Ramani (2008) are strongly dependent on the extent to which the child was allowed to control action over time.

When the observer-environment relation is pivotal, what then is perceived through action? These are certainly affordances. An affordance is a property that refers to the reciprocal relationship in which both environmental resources and the capabilities and dimensions of a child's body meet each other over time (Gibson \&Pick, 2000). Consequently, motor development can be defined as the extent to which an individual is increasingly fitted to his surroundings and becomes more and more skilled to detect, to differentiate and to recognise action properties afforded by his environment (Bongers, Smitsman, \& Michaels, 2003; Smitsman, Dejonckheere, \& De Wit, 2009). This brings us to the second aim of the present study: what is the relation between initial math learning and motor ability? For the development of mathematical concepts, such as understanding numbers, it is the object-perceiver or the event-perceiver relation, the discovery of what is afforded, that determines how first meanings develop (Gibson \& Pick, 2000). For instance, through the manipulation of a toy by an infant such as holding, rotating, throwing or squeezing, the infant discovers what is invariant over transformation: it is certain that an object has a shape, colour and size, but also that it is a unity since it differs from other objects and that it is separate from other things: "this is one object'. 'This is another object, it may be equal to the first one, yet it is another thing, these are two units'. In this example, the discovery of number, the meaning of number, is not derived from the event itself but directly emerges from the child's active exploration which is abstracted by the system.

What then is abstracted when a child plays on a digital number line on which action is only a metaphorical representation of real action? Indeed, the game we used in the present study was designed in such a way that virtual action on a number line is made possible. The child plays against a computer and tries to reach the end of the number line (0-10) as quickly as possible. To that end, he or she is allowed to move with one or two jumps. Moving along a path allows a child to extract meaning about certain math concepts in real time, even the action is rather metaphoric. For instance, zero equals the number origin, less than is closer to the origin, greater than is further away from the origin, moving away from the origin is addition and 
moving closer to the origin is subtraction (Lakoff \& Nuñez, 2000). The basis of number sense then refers to simple perception-action couplings for a concept that becomes increasingly abstract as its invariant aspect takes on usefulness in later exchanges of a social nature (Gibson \& Pick, 2000).

\section{Embodied Cognition}

The present study is in line with the theoretical stance that cognition is embodied. Embodied cognition argues that cognitive processes are grounded in a body's interaction with the environment and that body and environment impose significant limitations on inner organisation and processing (Soylu, 2011). For mathematical thinking, a considerable number of authors recognise that action is the location of mathematics (e.g. Lakoff \& Nuñez, 2000) and that the body itself is conceptualised as a necessary condition for mathematical sense (Bautista \& Roth, 2012). For instance, a study of Bautista and Roth (2011) showed how different forms of sonorous consciousness were involved in the emergence of mathematical knowing and the (re)production of mathematical communication. The authors argued that the development of knowledge emerges from unintended action that cannot be reduced to merely abstract ideas. For instance, they observed that embodied rhythmic patterns emerged in children's transactions with geometric objects and that dynamic contrasts (e.g. intensity, duration and rhythm) could specify conceptual properties of the object. They further saw that the intensity and temporal separation of the child's beats upon an object were used to describe the object in terms of its geometrical distinctions and similarities. Such findings underscore the fact that mathematical sense may be expressed both for the producer and for the recipient through action (Bautista \& Roth, 2011).

There are several studies that highlight the math-motor link. For example, Luo, Jose, Huntsinger and Pigott (2007) examined whether fine motor skills are related to the initial scores and growth rate of mathematics achievement in American kindergarteners and first graders. Results showed that fine motor skills significantly predicted their mathematics achievement over time. In another study, Westendorp, Hartman, Houwen, Smith and Visscher (2011) compared the gross motor skills of children with learning disabilities with those of normally developing children. The children were seven to twelve years old. The authors also investigated specific relationships between subsets of gross motor skills and children's academic performance in reading, spelling and mathematics. It was found that normally developing children outperformed children with learning disabilities on both object-control and 
locomotor tasks. Moreover, in children with learning disabilities a specific relationship was observed between reading and locomotor skills. Furthermore, a relationship between mathematics and object-control skills was discovered: the larger children's learning lag, the poorer their motor skill scores (Westendorp, Hartman, Houwen, Smith \& Visscher, 2011). Finally, children with mathematical learning disabilities performed significantly worse on visual perception, motor skills and visual-motor integration in comparison with age-matched controls (Pieters, Desoete, Roeyers, Vanderswalmen \& Van Waelvelde, 2012).

Stronger evidence about the math-motor link comes from physiological and neurological studies. This is because motor and cognitive functions use the same brain structures, follow a similar developmental time trajectory or have several underlying processes in common (e.g. monitoring and planning) (Westendorp, Hartman, Houwen, Smith \& Visscher, 2011). For instance, Andres, Seron, and Olivier (2007) argued that number processing activates a cortical network that is partly used for hand and finger movements. Concretely, the role of finger movements and hand motor circuits in learning counting was investigated. In order to test this hypothesis a repetitive Transcranial Magnetic Stimulation (rTMS) was used to monitor changes in corticospinal excitability during a counting task with numbers and letters. Interestingly, it was found that the excitability of the hand muscles increased during the task. The authors further argued that since excitability was found in both number and letter processing, hand motor circuits must be involved whenever items have to be put in correspondence with the elements of any ordered series (Andres, Seron \& Olivier, 2007).

Finally, in a study of Lopes, Santos, Pereira and Lopes (2012) associations between gross motor coordination and academic achievement in elementary school children were investigated. They found that in both genders, children with insufficient motor abilities had a higher probability of having low academic achievements when controlled for cardiorespiratory fitness, body mass index and socio-economic status. According to the authors the strong motor-academic achievements relation underscores the fact that providing opportunities for children to engage in a diversity of motor skills may play an important role in academic success.

\section{Objectives and hypotheses}

Given the above findings it can be questioned to what extend children with different motor abilities will perform on a number estimation task after they received several interven- 
tions in which action control on a digital number line was made possible. Given the above studies, significant correlations between the child's motor abilities and its scores on the number estimation task can be expected. In addition, it can be expected that children with better motor capacities and action control skills will show a stronger learning trajectory during our interventions with a digital number line. A better insight in the role of action for math learning could help us in verifying which affordances are worth to be implemented in digital tools.

\section{Method}

\section{Participants}

The dataset consisted of thirty-four first grade children with a mean age of 6 years and 6 months (range: 5 years and 9 months to 7 years and 7 months). Children were recruited from four different Flemish schools. The children of the first two schools were assigned to the experimental group $(\mathrm{N}=17)$, the other children were assigned to the control group $(\mathrm{N}=17)$. No children had experienced any learning disorders or serious problems with math before.

\section{Instruments}

Mouse test. During a mouse test it was investigated to what extent children were able to handle a computer mouse. The test consisted of a simple PowerPoint sheet presented on a laptop in front of the child. The sheet contained 6 blue circles set out over a green canvas. In the centre of the circles a number was written (1-6). The aim of the test was to click as fast as possible on each number in ascending order without making any mistakes.

Number Line test. This test consisted of 20 sheets of paper (A4). On each paper a thick black horizontal line of $24,2 \mathrm{~cm}$ was drawn. On the left side a ' 0 ' was written, on the right side a ' 10 '. Two centimetres above the line, in the middle, a number was written (1-10). The aim of the test was to estimate where the number should be located on the number line as accurately as possible.

BOT II. In order to assess child's motor abilities, the Bruininks-Oseretsky Test of Motor Proficiency (Bruininks \& Bruininks, 2005) was used. The BOT II is an instrument for measuring gross and fine motor skills in children, ranging from those who are normally developing to those with moderate motor-skill deficits. The tests consists of 8 subtests: 1) Fine Motor Precision -7 items (filling in a circle, filling in a star, drawing lines through crooked 
paths, drawing lines through curved paths, connecting dots, folding paper, cutting out a circle), 2) Fine Motor Integration-8 items (copying a circle, copying a square, copying overlapping circles, copying a wavy line, copying a triangle, copying a diamond, copying a star, copying overlapping pencils), 3) Manual Dexterity - 5 items (making dots in circles, transferring pennies, placing pegs into a pegboard, sorting cards, stringing blocks), Bilateral Coordination-7 items (Touching nose with index fingers and eyes closed, jumping jacks, jumping in place with the same sides synchronised, jumping in place with the opposite sides synchronised, pivoting thumbs and index fingers, tapping feet and fingers with the same sides synchronised, tapping feet and fingers with the opposite sides), 5) Balance-9 items (standing with feet apart on a line with the eyes open, walking forward on a line, standing on one leg on a line with the eyes open, standing with feet apart on a line with the eyes closed, walking forward heel-to-toe on a line, standing on one leg on a line with the eyes closed, standing on one leg on a balance beam with the eyes open, standing heel-to-toe on a balance beam, standing on one leg on a balance beam with the eyes closed), 6) Running Speed and Agility-5 items (shuttle run, stepping sideways over a balance beam, one-legged stationary hop, one-legged side hop, two-legged side hop), 7) Upper-Limb Coordination-7 items (dropping and catching a ball with both hands, catching a tossed ball with both hands, dropping and catching a ball with one hand, catching a tossed ball with one hand, dribbling a ball with one hand, dribbling a ball with alternating hands, throwing a ball at a target), 8) Strength -5 items (standing long jump, knee push-ups, sit-ups, wall sit, v-up).

For the present study we selected a limited number of items for fine motor performance: drawing lines through curved paths; cutting out a circle; copying a star and copying a square. In order to assess the gross motor performance another four items were selected: jumping in place with the same sides synchronised, one-legged stationary hop, dropping and catching a ball with both hands and dribbling a ball with alternating hands.

\section{Materials}

Number game. The intervention used in the present study consisted of playing a number game on 6 different moments. During the number game the child played against a computer. In the centre of the screen 11 blue coloured blocks were arranged in a horizontal line (for a screenshot, see Figure 1). In each of these blocks a number was written (1-10) with the exception of the first block in which the word 'start' was written. On the start square the pawn of the child and that of the computer could be found. Below the number line a two-coloured 
dice was shown. In the upper half of the dice number 1 was written, in the lower half number 2. For each game, the child was permitted to begin. Before a pawn could be moved, a dice had to be thrown by clicking it. Thereafter, the computer let an arrow turn and stopped it randomly, either on the upper half (1) or on the lower half (2). When a 'one' was selected, the child was allowed to move his pawn one block forward. In the other case, when a 'two' was selected, the pawn could be moved two consecutive blocks. Once this was done, the entire process was repeated by the computer (throwing the dice and moving its pawn). The purpose of the game was to be the first to reach the end of the line. The pawns could be moved by clicking the computer mouse and dragging the pawn one or two blocks further. When an error was made, the pawn returned to its initial location. When the child won the game a message appeared on the screen: 'Congratulations < name>, You Won!!!'

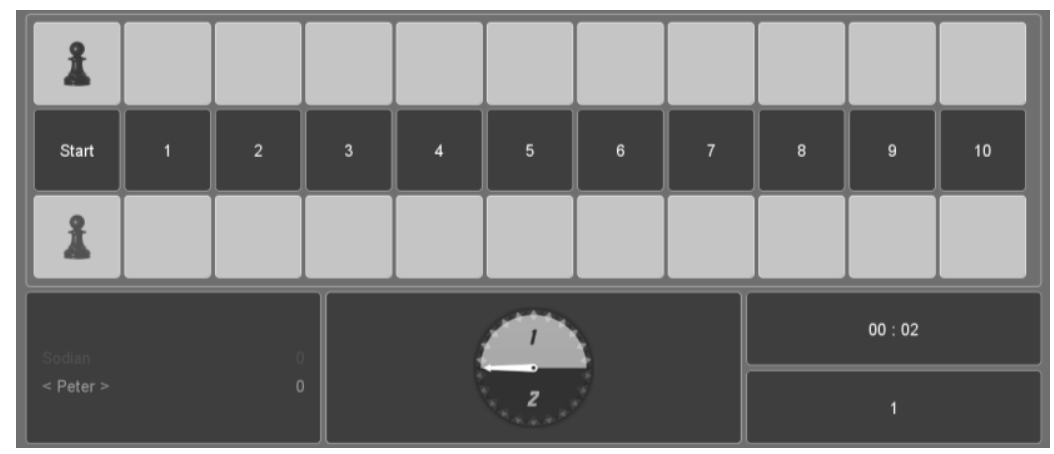

Figure 1: A screen shot of the number game used during the interventions.

\section{Procedure}

First of all, the mouse test and the BOT2 test took place on an individual basis. For the mouse test a child sat in front of a laptop on which 6 blue circles were depicted on a green canvas. The child was asked to click the numbers in ascending order as fast as possible. When an error was made (clicking out of the circle, skipping a number etc.) the experiment leader notified the child that a mistake had occurred and asked the child to continue with the previous number. The total time needed to do the test was measured from the moment the child clicked the first number until he or she clicked the final number. For the BOT 2 test the following instructions were given:

Drawing lines through curved paths: 'Here you see a curved line from this car to that house. Can you draw a line from the car to the house without crossing these boundaries? You have to do this as good and as fast as you can.' Time was measured as soon as the child put his ballpoint on the sheet of paper until it reached the house. The number of errors was 
counted (going outside the boundary line, an additional error was counted for each $1 / 2$ inch the child's line remained outside the boundary lines).

Cutting out a circle: 'Here you see a picture of a circle with a thick black line.' 'Can you cut this shape out of the sheet with these scissors?' 'Can you do this as to the best of your ability?' It was counted how many times the child went outside the black line.

Copying a star: 'Here a star is printed on your sheet. On the other side of your sheet you can copy this picture. Can you try to copy this star to the best of your ability? You are not allowed to turn your paper.' Scoring was based on different properties of the shape: the basic shape (good or bad), closure (good or bad), edges (good or bad), orientation (good or bad) and overall size (good or bad).

Copying a square: 'Here a square is printed on your sheet. On the other side of your sheet you can copy this picture. Can you try to copy this square to the best of your ability? You are not allowed to turn your paper.' Scoring was based on different properties of the shape: the basic shape (good or bad), closure (good or bad), edges (good or bad) and overall size (good or bad).

In order to assess gross motor performance another four items were selected:

Jumping in place with the same sides synchronised: 'Stretch your arm forward and place your foot of the same side forward. Now we are going to jump and at the same time we will be alternating our arms and legs. You have to jump until I say stop.' The number of correct jumps was recorded. A jump was incorrect when movements were discontinued or if the child failed to move leg and arm on the same side together. A maximum of two trials was allowed.

One-legged stationary hop: 'Place your feet together and your hands on your hip. Then, lift up a foot to the rear and jump. You may not alter your legs nor release your hands. Jump until I say stop.' The number of correct jumps within 15 seconds was counted. A jump was correct when the hands were on the hips and the child did not stumble or fall. A maximum of two trials was allowed.

Dropping and catching a ball with both hands: 'Stretch your arms in front of you and hold this tennis ball. Drop the ball and catch it with both hands, you may not hold the ball against your body. You can do this until I say stop.' The number of correct catches up to five was recorded in one trial. A catch was correct when the ball was caught with both hands and was not trapped against the body. 
Dribbling a ball with alternating hands: "Now we are going to do the same as the previous exercise with the exception that now you are only going to use one hand. Drop the ball with your hand and catch it with the other one. You can do this until I say stop.' The number of correct dribbles up to 10 was counted. When the hands were not alternated with each dribble or the ball bounced more than once, the dribble was seen as incorrect. Maximum two trials were allowed.

Before the intervention started the number line test took place. To that end, students got a bundle of 20 sheets of paper in random order. The test was done classically and was introduced by the teacher. The teacher gave the following instructions: "Which number do you see?', 'Okay, between 0 and 10 we can put other numbers, right?', 'Which number is presented above the line?', 'Okay, it is a 7, when this is 0 and this is 10 , where do you think 7 has to be located on that line?', 'You may now draw a short cross on the position you think the number 7 belongs.' Immediately after the number line test, the first intervention started. The intervention consisted of playing the number game in the pc classroom. Each child could play on an individual computer. The teacher said: 'You can type your name on the screen and then you can select a colour for the pawn that you want to play with. Click the arrow now and you will see that the arrow turns around. When the arrow stops at number 1, you may pick up your pawn and move it only one block further. When number 2 is selected, you may move your pawn twice. After you have done this, it is the computer's turn.' While the teacher gave the instructions all children saw how the game could be played on a big screen in front of the classroom. The game was played for 15 minutes on six different days within two weeks. The number of times played in one session ranged from 5 to 12 times.

\section{Design \& Statistical Analysis}

The experiment consisted of three different phases. In the first phase a pre-test was done, which consisted of assessing 1) mouse handling precision and 2) gross and fine motor performances with the BOT II (Bruininks \& Bruininks, 2005) and 3) number line estimation. The second phase of the experiment was the intervention in which children could play with the number game on a personal computer during six sessions. Finally, in a post-test (third phase) children were asked to do the number line test again. Controls did the same with the exception that they did not play the number game.

Baseline Statistics. Firstly, it was analysed to what extent pre-test results differed between experimentals and controls for the following variables: gender, mouse test, fine motor 
performance and gross motor performance. Therefore a multivariate analysis of variance (MANOVA) was executed with the scores of the mouse test, the fine motor and the gross motor scores as dependent variables and group (experimentals versus controls) and gender as independent variables.

Percent Absolute Error. With the aid of children's estimates on the number line, a measure of accuracy was calculated using the following formula:

$$
P A E=\sqrt{\left(\frac{\text { estimate }- \text { estimated quantity }}{\text { scale of } \text { estimated }}\right)^{2}}
$$

For instance, a child has to estimate the location of number 5 on the number line but in reality it places a mark at the location that corresponds to 3. The percent absolute error then equals:

$P A E=\sqrt{\left(\frac{3-5}{10}\right)^{2}}=0.2$ or $20 \%$, thus the higher the percent is, the worse the estimation accuracy.

In order to analyse the PAEs for controls and experimentals between pre-test and posttest an analysis of variance was executed with repeated measures. To that end, the group (experimentals versus controls) acted as independent variable whereas the percent absolute errors (PAE) in pre-test and post-test acted as a dependent variable (within).

Linearity of estimation. We analysed individual estimation data through computing a best fitting linear function $\left(=\mathrm{R}^{2} \mathrm{Lin}\right)$ on the basis of the scatter plot of each participant's actual and estimated numbers.

Percent absolute error (PAE) and motor scores. In order to analyse the relationship between fine motor and gross motor performances on the one hand and the percent absolute error scores (PAE) on the other hand, we executed an analysis of covariance (ANCOVA) with repeated measures. Gross motor (within subjects) and fine motor (within subjects) performances acted as independent variables. Gross motor and fine motor were both kept as continuous variables and introduced in the analysis as covariates. We ran the analysis twice, first for experimentals and then for controls.

Linearity of estimation $\left(R^{2}\right)$ and motor scores. Similar to the previous analysis, we investigated the effect of both gross motor and fine motor scores on the individual $\mathrm{R}^{2}$ lin with the aid of an analysis of covariance (ANCOVA) for experimentals and controls separately. 
Correlations. Bivariate correlations were calculated between the children's motor abilities (fine and gross motor) and the scores on the number line in the pre-test (PAE and $\left.\mathrm{R}^{2} \operatorname{Lin}\right)$.

\section{Results}

Baseline Statistics. Results did not reveal significant differences (all $F$ 's $<3$ ) between the experimental group and the control group and between boys and girls (all $F$ 's $<2$ ) for the different variables: mouse test, fine motor performance and gross motor performance.

Percent Absolute Error. Results revealed a main effect of pre-test versus post-test, in which significantly less errors were made in the post-test, $F(1,32)=15,36 ; p<0.001$, partial $\eta^{2}=0,32$, (MPAE-pre=25,56; $S D=12,54 ;$ P PAE-post=20,35, $\left.S D=12,67\right)$. In addition, a significant main effect of the group (experimentals versus controls) was observed, $F(1,32)=5,07$; $p<0.03$; partial $\eta^{2}=0,14$. Finally, the interaction of pre-test versus post-test with the group for PAE proved to be significant, $F(1,32)=10,02 ; p<0.003)$, see Figure 2 .

In addition, an analysis of the individual estimates for linearity yielded the following results. For controls, $77 \%$ of the variance in the pre-test was explained by the best fitted linear function, this was again $76 \%$ in the post-test. For experimentals, the best linear function accounted for $77 \%$ of the variance in the pre-test and increased a little to $85 \%$ in the post-test (see Figure 3). In addition, with an analysis with repeated measures in which the dependent variable was $\mathrm{R}^{2}$ Lin in the pre-test and the post-test and the independent variable was the group (experimental versus control group), the interaction of pre-test versus post-test and group (experimental versus control group) for $\mathrm{R}^{2}$ Lin tended to be significant, $F(1,32)=3,81$; $p=0.06$, partial $\eta^{2}=0,11$. Main effects of group and pre-test versus post-test were not significant $(F<3)$. 


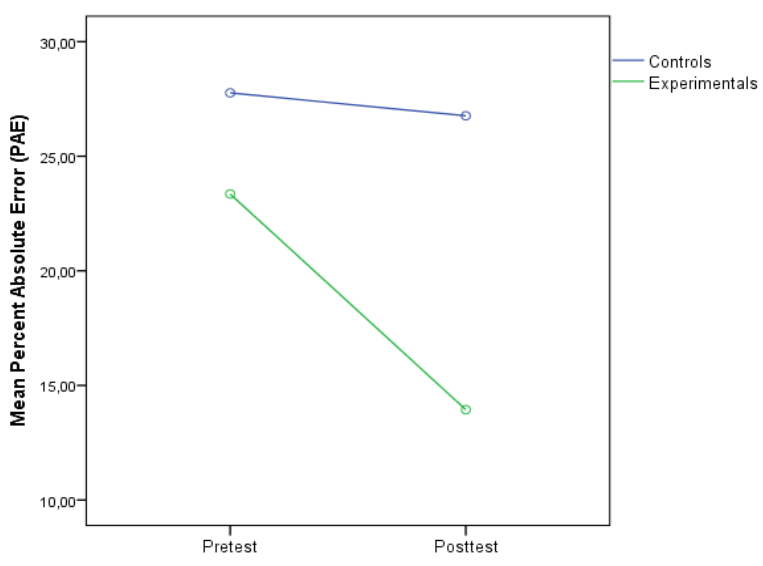

Figure 2: Mean percent absolute errors in the pre-test and the post-test for controls and experimental

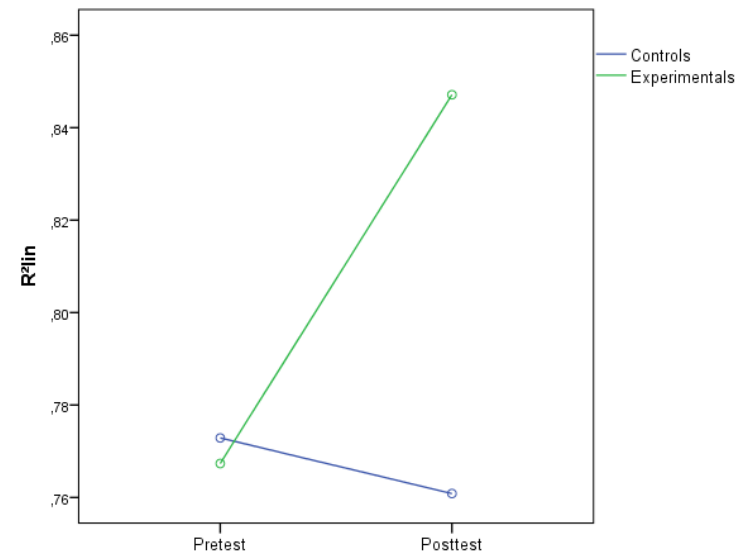

Figure 3: Best fitting linear functions (means of $\mathbf{R}^{2} \mathbf{L i n}$ ) from pre-test to post-test for experimentals and controls

Percent absolute error (PAE) and motor scores. For experimentals a significant main effect of the gross motor covariate on the percent absolute error (PAE) emerged, $F(1,14)=12,21 ; p<0,004$; partial $\left.\eta^{2}=0,47\right)$. In addition, the difference between percent absolute errors (PAE) in the pre-test and the post-test depended on the gross motor covariate $\left(F(1,14)=6,37 ; p<0,03\right.$, partial $\left.\eta^{2}=0,31\right)$. No such effects were found for controls $(F<2)$. In order to make the gross motor covariate and the means of PAE visible in the experimental group, we dichotomised the motor scores with the aid of a median split (see Figure 4). 


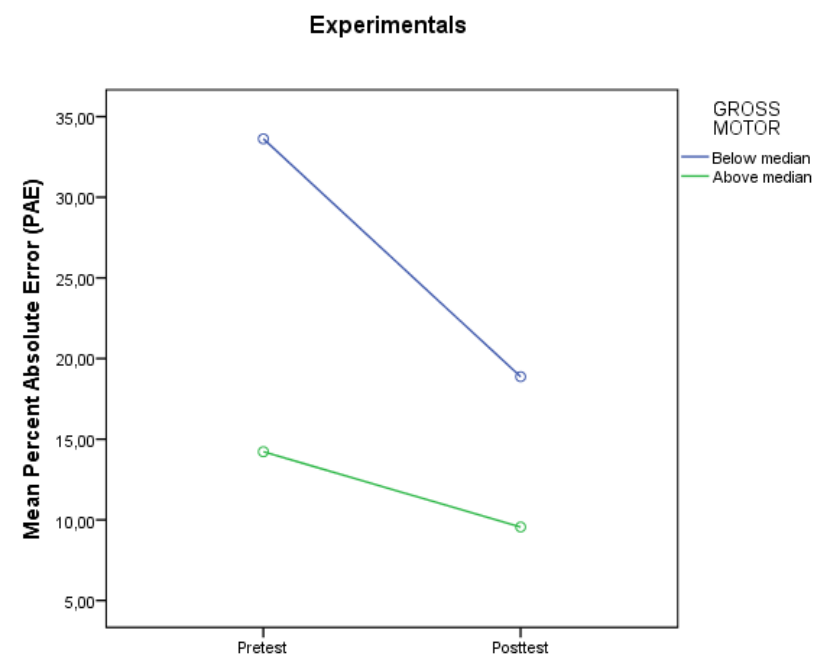

Figure 4: Mean percent absolute errors in the pre-test and the post-test for children with gross motor scores below and above the median.

Linearity of estimation $\left(R^{2}\right)$ and motor scores. Results revealed no significant effects of the covariates on the dependent variable ( $\left.\mathrm{R}^{2} \mathrm{Lin}\right)$, neither did the covariates show a significant interaction with the pre-test-post-test within variable (all $F$ 's<3).

Correlations. These correlations are presented after a Bonferroni correction (the new cut-off level of significance is then $0.05 / 6=0.0083$ ) in Table 1. A significant correlation emerged between gross motor and PAE (pre-test), $r=-.48$ ( $p=.004)$. Other correlations did not reach the $0,83 \%$ significance level.

Table 1: Bivariate correlations for fine motor, gross motor, PAE (pre-test) and $R^{2} \operatorname{Lin}($ pre-test)

\begin{tabular}{|c|c|c|c|c|}
\hline Scale & Fine Motor & $\begin{array}{l}\text { Gross Mo- } \\
\text { tor }\end{array}$ & $\begin{array}{c}\text { PAE (pre- } \\
\text { test) }\end{array}$ & $\begin{array}{l}\mathrm{R}^{2} \text { Lin (pre- } \\
\text { test) }\end{array}$ \\
\hline Fine Motor & - & ,07 & , 14 &,- 17 \\
\hline $\begin{array}{l}\text { Gross Mo- } \\
\text { tor }\end{array}$ & & - &,$- 48^{*}$ & ,08 \\
\hline $\begin{array}{l}\text { PAE (pre- } \\
\text { test) }\end{array}$ & & & - &,- 25 \\
\hline $\begin{array}{l}\mathrm{R}^{2} \mathrm{Lin} \text { (pre- } \\
\text { test) }\end{array}$ & & & & - \\
\hline
\end{tabular}




\section{Discussion and Conclusions}

In the present study it was investigated to what extent number learning with a digital tool and action control was related to a child's normal motor abilities. The tool was a digital translation of the number game of Siegler and Ramani (2008). It was suggested that through sensorimotor action, even virtual, the child was able to abstract meaning about number concepts in real time. Because of the fact that cognition is often constrained by a child's developing motor abilities, we questioned whether its gross and fine motor scores for a limited set of BOT-2 subtests were able to explain how much a child would benefit from playing with a digital number game during a two-week intervention programme.

Firstly, our results indicated a positive correlation between gross motor and the percent absolute error (PAE). However, we didn't observe a significant relationship between fine motor and PAE. This is possible due to the fact that fine motor skills develop later than gross motor skills, which may result in a higher variability for fine motor skills at that age. In addition, we did not found a correlation between gross motor skills (and fine motor skills) and children's best fitting linear functions $\left(\mathrm{R}^{2} \mathrm{Lin}\right)$. This may indicate that PAEs are more powerful tools to measure knowledge of numerical magnitudes with participants coming from middle-income families with a normal range of motor abilities. However, our results are in line with studies that suggest a link between mathematical achievements and motor performance (e.g. Burns, O’Callaghan, McDonell \& Rogers, 2004; Piek, Dawson, Smith \& Gasson, 2008), that gross motor proficiency is able to foster academic achievement (e.g. Son \& Meisels, 2006; Westendorp, Hartman, Houwen, Smith \&Visscher, 2011) and that a child's learning gain is constrained by its own motor abilities (e.g. Goddard Blythe, 2000; Wassenberg, et al., 2005). Secondly, we found a significant drop in the percent absolute errors between number line pre-tests and post-tests of experimentals but not in controls. In addition, in contrast to controls, we observed an increase in children's best fitting linear functions ( $\left.\mathrm{R}^{2} \mathrm{Lin}\right)$. These results are in line with Siegler and Ramani (2008). Finally, an analysis of covariance revealed a significant main effect of the gross motor covariate on the dependent variable (PAE). Additionally, we found a significant interaction between the gross motor covariate and the PAEs in the pre and post-test. The latter means that the covariate (gross motor) had a significant effect on the relationship between gross motor and pre-test-post-test PAEs. No such effects were found for $\mathrm{R}^{2} \mathrm{Lin}$. In addition, when the effect of the covariate was visualised through dichotomising the PAE scores with a median split, it was shown that children with gross motor 
scores below the median benefitted more from the digital tool intervention. For children with gross motor scores above the median no differences between pre-test and post-test emerged.

We hypothesised that within a normal range of skills children with better motor capacities would benefit significantly more from the intervention in which action control was crucial. In contrast, we saw that for lower motor children, their percent absolute errors (PAEs) significantly decreased from pre-test to post-test. In other words, they made fewer errors in the post-test. We did not found such a learning trajectory in children with higher motor abilities. Thus, it was shown that when children with gross motor skills below the median were provided several intervention sessions with a digital number line, estimation accuracy for numbers was improved to the point where it was indistinguishable from that of children with gross motor abilities above the median. Unfortunately, the present study is not able to isolate the effect of motor performance from general intelligence and problem solving. We only can suggest that a digital intervention for number learning in which action control is allowed is prevailingly suitable for children with lower capacities. However, our results reveal a child's need for action-based and physical representations of numbers when their skills, including motor skills, are rather poor. The action-based representations may then strengthened the child's perceptual sensitivity and open opportunities to abstract meaning about number concepts in real time. In contrast, children with better (motor) capacities may be more inclined to use internal math models or mental representations, making the intervention redundant and resulting in a flat learning trajectory form pre-test to post-test. For these children it is reasonable to say that thinking on number lines has become a simulation of a sensorimotor process in which physical input and output has been decoupled. Soylu (2011) mentioned the example of finger counting. Initially, finger counting is an explicit sensorimotor behaviour whereby an observer actually sees the child's fingers moving. However, with growing maturity, finger counting becomes more and more subtle. The activity is then 'pushed inward' while its neural motor organisations are still active without overt behaviour. The counting is then a sensorimotor simulation.

According to Goddord-Blythe (2000), the most advanced level of motor control is being able to stay motionless. In such a situation a child has to hold its own action system stable over time in which parameters of posture, balance etc. are controlled. As a consequence, learning to write is difficult when children have difficulties with controlling their eye movements and postural system. In the same way, for reading, attention is needed. This atten- 
tion develops as the child matures, while the level of motor performance is a measure of maturity. This may indicate that body control, the development of body image and having a sense of directionality are prerequisites for further learning in different academic contexts such as reading, writing and arithmetic. As a consequence, an increased emphasis on academic achievements without having an eye for a child's less developed motor performance is for some an inefficient way to strengthen academic success (Goddord-Blythe, 2000).

Another possible explanation for the present results comes from Lopes, Santos, Pereira and Lopes (2012) who argue that better gross motor results may reflect a better health and physical fitness. In this way cognitive facilitation by physical activities is attributable to a strengthened cerebral blood circulation and the alteration of neurotransmitter actions. They also suggested that children with poorer motor abilities participate less in organised and freeplay activities which are persistent over time. According to the authors it is then possible that these children did not get the same opportunities to enhance their academic achievements given the benefits of physical activities which can explain the need for an action-based representation in the present intervention tool.

The present study is not able to find out which explanation is the right one. However, as in many studies, our results highlight the link between motor and early math learning and underscore that through action-based digital tools, learning is supported for children with lower motor abilities. This is also in line with learning mathematics with manipulatives in an everyday school practice (e.g. Moyer-Packenham, Salkind \& Bolyard; 2008, Reimer \& Moyer, 2005). The use of manipulatives for math allows a teacher to make abstract concepts more concrete and tactile. Recently, manipulatives have become increasingly virtual whereby the digital objects involved resemble their physical counterparts. However, the digital tool of the present study is more than just a simple virtual manipulative in which a visual representation of a mathematical concept is coupled to the symbolic notion of that concept. Indeed, the present tool allows a child to extend physical experience and to develop an initial understanding of complex ideas (Moyer-Packenham, Salkind \& Bolyard, 2008) but the role of action is prominent.

\section{Limitations and Future Research}

Firstly, the present study is not able to isolate the effect of motor performance from general intelligence and problem solving. However, we found some indactions that action- 
based representations open opportunities to abstract meaning about number concepts in real time. Secondly, we did not measure directly to what extent a child abstracts meaning from virtual action in a digital tool task. We only observed an association between motor and early math learning. Therefore, future research has to find out how learning outcomes evolve when a child plays on a digital number line in which the amount of action possibilities is varied (for instance on a tablet system).

\section{Conclusions}

The present study shows an association between motor abilities and number estimation. This is in line with numerous motor/math studies and studies that recommend the use of concrete materials for early math problem solving. In addition it was shown that the lower the motor abilities of the child, the more he or she benefitted from the intervention. This result may refer to the fact that these children were in need of action-based representations in math interventions, even in the form of a digital tool. Action-based representations strengthen a child's perceptual sensitivity, which amplifies the chance of extracting meaning of number. Therefore, when designing digital tools, one should have an eye for action properties and action control.

\section{References}

Andres, M., Seron, X., \& Olivier, E. (2007). Contribution of hand motor circuits to counting. Journal of Cognitive Neuroscience, 19(4), 563-576. doi: 10.1162/jocn.2007.19.4.563

Antle, A.N., Corness, G., \& Droumeva, M. (2012). What the Body Knows: Exploring the Benefits of Embodied Metaphors in Hybrid Physical Digital Environments, Interact ing with Computers, 21(1-2), 66-75. doi: 10.1016/j.intcom.2008.10.005

Bautista, A., Roth, W. (2011). Conceptualizing sound as a form of incarnate mathematical consciousness. Educational Studies in Mathematics, 79 (1), 41 - 59. doi 10.1007/s10649-011-9337-y

Bongers, R.M., Smitsman, A.W., \& Michaels, C.F. (2003). Geometrics and dynamics of a rod Determine how it is used for reaching. Journal Of Motor Behavior, 35(1), 4-22.

Burns, Y., O’Callaghan, M., McDonell, B. \& Rogers, Y. (2004). Movement and motor devel opment in ELBW infants at 1 year is related to cognitive and motor abilities at 4 years. Early Human Development, 80, 19-29. 
Gibson, E. J., \& Pick, A. D. (2000). An Ecological Approach to Perceptual Learning and Development. Oxford: Oxford University Press.

Goddard-Blythe, S. (2000). Early learning in the balance: priming the first ABC. Support for Learning, 15(4), 154-158. doi: 10.1111/1467-9604.00168

Lakoff, G., \& Núñez, R. (2000). Where Mathematics Comes From: How the Embodied Mind Brings Mathematics into Being. New York: Basic Books.

Lopes, L., Santos, R., Pereira, B., \& Lopes, V.P. (2013). Associations between gross Motor Coordination and Academic Achievement in elementary school children. Human Movement Science, 32(1), 9-20. doi: 10.1016/j.humov.2012.05.005

Moyer-Packenham, P.S., Salkind, G., \& Bolyard, J.J. (2008). Virtual manipulatives used by K-8 teachers for mathematics instruction: Considering mathematical, cognitive, and pedagogical fidelity. Contemporary Issues in Technology and Teacher Education, $8(3), 202-218$.

Piek, J. P., Dawson, L., Smith, L.M., \& Gasson, N. (2008). The role of early fine and gross motor development on later motor and cognitive ability. Human Movement Science, 27, 668-681. doi: 10.1016/j.humov.2010.03.006

Pieters, S., Desoete, A., Roeyers, H., Vanderswalmen, R., \& Van Waelvelde, H. (2012). Be hind mathematical learning disabilities: What about visual perception and motor skills? Learning and Individual Differences, 22(4), 498-504. doi: 10.1016/j.lindif.2012.03.014

Räsänen, P., Salminen, J., Wilson, A.J., Aunio, P., \& Dehaene, S. (2009). Computer-assisted intervention for children with low numeracy skills. Cognitive Development 24(4), 450472. doi: 10.1016/j.cogdev.2009.09.003

Reimer, K., \& Moyer, P.S. (2005). Third graders learn about fractions using virtual manipula tives: A classroom study. Journal of Computers in Mathematics and Science Teach ing, 24(1), 5-25.

Smitsman, A.W., Dejonckheere, P.J.N., \& De Wit, T (2009). The significance of event infor mation for 6- to 16-month-old infants' perception of containment. Developmental Psy chology, 45(1), 207-23. doi: 10.1037/a0014034

Soylu, F. (2011). Mathematical Cognition as Embodied Simulation. Proceedings of the 33rd Annual Conference of the Cognitive Science Society, 1217-1217.

Siegler, R.S., \& Ramani, G.B. (2008). Playing linear numerical board games promotes lowincome children's numerical development. Developmental Science, 11, 655-661. doi: $10.1037 / \mathrm{a} 0014239$ 
Westendorp, M., Hartman, E., Houwen, S., Smith, J., \& Visscher, C. (2011). The relationship between gross motor skills and academic achievement in children with learning disabilities. Research in Developmental Disabilities, 32(6), 2773-2779. doi: 10.1016/j.ridd.2011.05.032

Winn, W.D., \& Windschitl, M. (2001). Learning in artificial environments. Cybernetics and Human Knowing, 8(4), 5-23.

Winn, W. (2003). Learning in artificial environments: embodiment, embeddedness and dy namic adaptation. Technology, Instruction, Cognition and Learning, 1, 87-114.

Wassenberg, R., Feron, F.J.M., Kessels, A.G.H., Hendriksen, J.G.M., Kalff, A.C., Kroes, M.,

Hurks, P.P.M., Beeren, M., Jolles J., \& Vles, J.S.H. (2005). Relation between cognitive and motor performance in 5- to six-year-old children: results from a large-scale crosssectional study. Child Development, 76(5), 1092-1103. 